\title{
Analisis Strategi Penerapan Teknologi Informasi Dengan Menggunakan Metode SWOT dan IT Balanced Scorecard (Studi Kasus : PT Telekomunikasi Indonesia Sub Divisi Satelit)
}

\author{
Sari Setyaning Tyas \\ Politeknik Negeri Media Kreatif, Jl Srengseng sawah Jagakarsa Jakarta Selatan 12640
}

\section{INFORMASI ARTIKEL}

Diterbitkan Online: 15 Juli 2019

\section{KATA KUNCI}

Sub Divisi Satelit, SWOT, IT Balanced Scorecard

\section{KORESPONDENSI}

E-mail Dosen: sarist@polimedia.ac.id

\begin{abstract}
A $\quad$ B $\quad S \quad T \quad R$ A $\mathbf{C}$ T
Sub Divisi Satelit PT Telekomunikasi Indonesia merupakan satu-satunya perusahaan BUMN yang menangani layanan komunikasi satelit di Indonesia. Tujuan dari studi kasus ini adalah menganalisa efektifitas strategi teknologi informasi yang diterapkan pada PT Telekomunikasi Indonesia khususnya Sub Divisi Satelit dengan menggunakan metode SWOT dan IT Balanced Scorecard. Proses analisa strategi teknologi informasi tersebut dilakukan pada pengguna aplikasi yang merupakan staf dari Sub Divisi Satelit. Hasil dari analisa pada matriks SWOT menunjukan bahwa Sub Divisi Satelit berada pada kuadran SO dengan titik koordinat (1.98 dan 1.05), dimana perusahaan berada pada situasi yang sangat menguntungkan. Hasil analisis IT Balanced Scorecard menunjukan pencapaian Sub Divisi Satelit berada pada kategori very good. Hasil dari analisa SWOT dan IT Balanced Scorecard tersebut akan dianalisis, sehingga menghasilkan suatu rekomendasi yang bermanfaat bagi perusahaan demi mencapai tujuan bersama.
\end{abstract}

\section{PENDAHULUAN}

Di Indonesia, industri telekomunikasi sendiri telah memasuki momentumnya seiring dengan semakin tingginya kesadaran serta pengetahuan masyarakat terhadap produk dan layanan berbasis teknologi informasi serta manfaatnya terhadap kehidupan. Populasi Indonesia yang besar serta pertumbuhan ekonominya yang tertinggi di kawasan Asia Tenggara menawarkan peluang tersendiri bagi kelanjutan bisnis di industri telekomunikasi sehingga memperbesar pangsa pasar telekomunikasi itu sendiri.

Namun, dalam upaya pengembangan jaringan telekomunikasi di Indonesia, tentunya menjadi kendala tersendiri bagi Indonesia yang terdiri dari pulau-pulau yang berkontur alam pegunungan dan terpisahkan oleh laut-laut. PT Telekomunikasi Indonesia sebagai Badan Usaha Milik Negara (BUMN) dan penyedia layanan telekomunikasi dan jaringan terbesar di Indonesia, dihadapkan pada tantangan pengembangan infrastruktur dalam rangka memenuhi kebutuhan atas akses terhadap layanan telekomunikasi yang berkualitas bagi penduduk di daerah terpencil. Kondisi geografis Indonesia yang demikian rumitnya menjadikan satelit cocok diterapkan untuk sistem komunikasi di Indonesia. Penerapan teknologi informasi satelit tersebut ditangani oleh salah satu subdivisi yang ada pada PT Telekomunikasi Indonesia yakni Sub Divisi Satelit.

\section{METODE PENELITIAN}

Hasil yang diharapkan dari penelitian ini adalah mengetahui permasalahan yang terjadi sehingga menghasilkan rekomendasi yang dapat digunakan untuk perbaikan kinerja perusahaan dan bagaimana cara terbaik bagi perusahaan untuk dapat mengoptimalkan sumber daya informasi yang tersedia serta hal apa saja yang menjadi prioritas untuk menunjang kebutuhan pengguna demi mencapai tujuan bersama. Oleh karena itu, penulis menggunakan metode Analisis Gap diawal penelitan serta metode analisis SWOT dan IT Balanced Scorecard.

Ada beberapa tahapan yang akan dilakukan dalam studi kasus ini antara lain adalah sebagai brerikut:

- Identifikasi perumusan masalah studi kasus pada PT Telekomunikasi Indonesia sub divisi satelit. Penulis melakukan analisis awal dengan analisis Gap.

- Menentukan tujuan dan ruang lingkup penelitian.

- Melakukan studi literatur dan mencari sumber referensi.

- Mengumpulkan fakta dan data, penelitian dimulai pada bulan Mei 2012 bertempat di kantor PT Telekomunikasi Indonesia, Sub Divisi Satelit, Divisi Infratel SPU Cibinong, yang berlokasi di Jl.Raya Narogong Km 26,5 Klapanunggal Bogor.

Melakukan pengukuran dengan analisa SWOT dan analisa IT Balanced Scorecard. Penulis akan 
menganalisa strategi teknologi informasi yang digunakan oleh PT Telekomunikasi Indonesia Sub Divisi Satelit. Selanjutnya penulis berharap agar apa yang dihasilkan dapat menjadi acuan untuk analisa sistem teknologi informasi selanjutnya.

\section{Analisis Gap}

Penulis melakukan analisa Gap berdasarkan pada sistem informasi yang diimplementasikan oleh perusahaan melalui sudut pandang performa dan espektasi yang diharapkan oleh staf dalam pengelolaan SI/TI. Diharapkan analisis Gap dapat menghasilkan pemahaman bersama bagaimana cara terbaik bagi perusahaan untuk dapat mengoptimalkan sumber daya informasi yang tersedia.

\section{Analisa SWOT}

Untuk memahami kondisi yang ada pada perusahaan saat ini, maka dilakukan analisa faktor internal dan eksternal pada PT Telekomunikasi Indonesia khususnya Sub Divisi Satelit dengan melakukan analisa SWOT. Analisa SWOT ini bersumber dari wawancara kepada bagian ASMAN Help Desk dan annual report 2011.

\section{Analisa IT Balanced Scorecard}

Pengukuran IT Balanced Scorecard terdiri dari 4 persektif, yaitu perspektif kontribusi perusahaan, perspektif orientasi pengguna, perspektif penyempurnaan operasional dan perspektif orientasi masa depan. Dengan pengukuran IT Balanced Scorecard diharapkan nantinya kita dapat melihat apakah teknologi informasi yang diimplementasikan oleh perusahaan sudah sesuai dengan visi, misi dan strategi perusahaan.

- Diharapkan dengan ketiga analisis tersebut yaitu analisis Gap, analisa SWOT dan analisa IT Balanced Scorecard akan dihasilkan laporan yang dapat dijadikan acuan bagi PT Telekomunikasi Indonesia Sub Divisi Satelit. Hasil laporan tersebut diharapkan dapat memberikan rekomendasi yang bermanfaat bagi perusahaan demi mencapai tujuan bersama.

- Membuat kesimpulan dan saran

\section{APLIKASI TI PADA SUB DIVISI SATELIT}

Aplikasi berikut adalah aplikasi yang digunakan Sub Divisi Satelit dalam melakukan monitoring performa satelit Telkom-1 dan Telkom-2. Aplikasi ini digunakan mulai tahun 2008 berikut penjelasan aplikasi yang digunakan :

a. Simponi, merupakan aplikasi basis data yang mengelola sistem informasi alat produksi, jumlah kapasitas satelit, kapasitas transponder dan kapasitas dari stasiun bumi.

b. Network Management System (NMS), merupakan aplikasi pengendalian jaringan (remote jarak jauh), digunakan untuk melakukan evaluasi performa pada jaringan.

c. SIECAMS, merupakan alat ukur yang digunakan untuk melacak gangguan, seperti gangguan tarif liar dan gangguan pemancar lain yang dapat mempengaruhi kualitas dari transponder.

\section{HASIL DAN PEMBAHASAN}

\section{Analisis Gap}

Analisis gap merupakan suatu pengukuran evaluasi yang berdasarkan pada sistem informasi yang diimplementasikan oleh perusahaan melalui sudut pandang espektasi (kepentingan) dan performa. Dalam melakukan pengukuran, bertindak sebagai responden adalah staff sistem informasi dan pengguna sistem "user"[1].

Sebagai tahap awal, penulis memulai studi kasus ini dengan melakukan analisis Gap pada Sub Divisi Satelit. Penggunaan metode analisis Gap secara tidak langsung dimaksudkan untuk merumuskan permasalahan awal yang ada pada Sub Divisi Satelit. Penulis melakukan analisis Gap di penelitian awal pada Sub Divisi Satelit, hasilnya dapat dijabarkan sebagai berikut, Peringkat lima teratas mean espektasi adalah sebagai berikut :

Tabel 1. Peringkat Lima Teratas Mean Espektasi

\begin{tabular}{cl}
\hline Rank & \multicolumn{1}{c}{ Attribute } \\
\hline $\mathbf{1}$ & Perangkat keras yang up to date (soal no 2) \\
\hline $\mathbf{2}$ & $\begin{array}{l}\text { Kemudahan pengguna dalam mengakses fasilitas } \\
\text { komputansi (soal no 1) }\end{array}$ \\
\hline $\mathbf{3}$ & Tingkat pelatihan pengguna (soal no 11) \\
\hline $\mathbf{4}$ & $\begin{array}{l}\text { Sikap yang positif dari staf SI kepada pengguna (soal } \\
\text { no 15) }\end{array}$ \\
\hline $\mathbf{5}$ & Dokumentasi untuk mendukung pelatihan (soal no 20)
\end{tabular}

Peringkat lima teratas mean performa adalah sebagai berikut :

Tabel 2. Peringkat Lima Teratas Mean Performa

\begin{tabular}{|c|c|c|c|}
\hline Rank & \multicolumn{3}{|c|}{ Attribute } \\
\hline $\mathbf{1}$ & \multicolumn{3}{|c|}{$\begin{array}{l}\text { Kemudahan pengguna dalam mengakses fasilitas } \\
\text { komputansi (soal no } 1 \text { ) }\end{array}$} \\
\hline 2 & $\begin{array}{l}\text { Presentase } \\
\text { rendah } \\
\text { Software }\end{array}$ & $\begin{array}{l}\text { downtime } \\
\text { pada hardware }\end{array}$ & $\begin{array}{l}\text { yang } \\
\text { dan }\end{array}$ \\
\hline 3 & \multicolumn{3}{|c|}{$\begin{array}{l}\text { Staff pembantu sistem yang memiliki teknikal } \\
\text { kompetensi yang baik (soal no 6) }\end{array}$} \\
\hline 4 & \multicolumn{3}{|c|}{ Kepercayaan pengguna terhadap sistem (soal no 7) } \\
\hline 5 & \multicolumn{3}{|c|}{$\begin{array}{l}\text { Tingkat pengendalian pengguna terhadap sistem (soal } \\
\text { no } 8 \text { ) }\end{array}$} \\
\hline
\end{tabular}

Berdasarkan perhitungan, terdapat 4 atribut yang memiliki nilai perceptual gap negatif, diantaranya :

$\checkmark \quad$ Perangkat keras yang up to date (atribut no 2).

$\checkmark$ Tingkat pelatihan pengguna (atribut no 11).

$\checkmark \quad$ Sikap yang positif dari staf SI kepada pengguna (atribut no 15).

$\checkmark \quad$ Dokumentasi untuk mendukung pelatihan (atribut no 20).

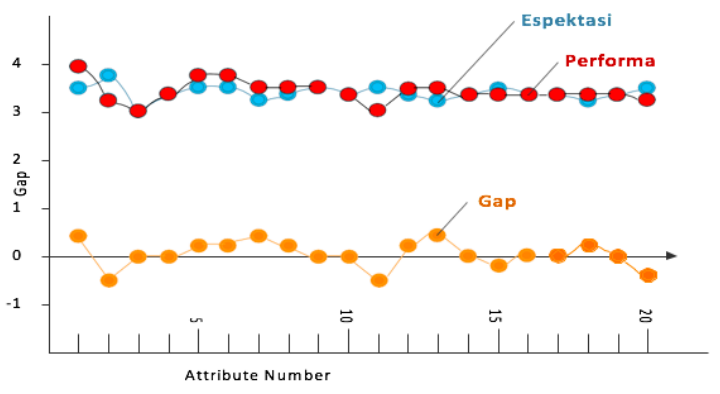

Gambar 2. Diagram Ular

Terdapat 4 point yang harus menjadi fokus perhatian bagi perusahaan, diantaranya : 
- $\quad$ Perangkat keras yang up to date (atribut no 2). Terjadi gap 0.55 , maka dapat disimpulkan bahwa pengguna menginginkan perangkat keras yang up to date.

- Tingkat pelatihan pengguna (atribut no 11). Terjadi gap -0.55 , maka dapat disimpulkan bahwa pengguna membutuhkan adanya tambahan frekuensi pelatihan bagi para staf pengguna dan staf TI. Agar pekerjaan dapat diselesaikan dengan tepat waktu dan apabila terdapat permasalahan dapat diselesaikan dengan cepat dan tepat.

- $\quad$ Sikap yang positif dari staf TI kepada pengguna (atribut no 15). Terjadi gap - 0.17, maka dapat disimpulkan bahwa pengguna ingin mendapat pelatihan teknis dalam menjalankan aplikasi (hardware dan software) agar dapat menyelesaikan pekerjaan dengan tepat waktu.

- Dokumentasi untuk mendukung pelatihan (atribut no 20). Terjadi gap -0.33, maka dapat disimpulkan bahwa perlunya untuk melakukan penyusunan standar acuan untuk perangkat keras dan piranti lunak.

\section{Analisis SWOT}

Secara konsep manajemen strategi dimulai dengan penyesuaian perusahaanya dengan lingkungan kepada kekuatan (strength), kelemahan (weakness), peluang (opportunities), dan ancaman (threats) dari perusahaan tersebut, atau dikenal dengan analisis SWOT [4]. Penggunaan analisis SWOT dilakukan dengan tujuan untuk mengetahui kondisi perusahaan baik dari lingkungan internal perusahaan maupun lingkungan eksternal perusahaan.

Tabel 4. Analisis Lingkungan Internal dan Eksternal Sub Divisi Satelit

\begin{tabular}{|c|c|c|c|}
\hline kode & Kekuatan (Strengths) & kode & Kelemahan (Weaknesses) \\
\hline S1 & $\begin{array}{l}\text { Memiliki infrastruktur ICT yang } \\
\text { lengkap dan handal }\end{array}$ & W1 & $\begin{array}{l}\text { Beragamnya interface dan perangkat } \\
\text { protokol yang dioperasikan }\end{array}$ \\
\hline s2 & $\begin{array}{l}\text { Memiliki human resource yang } \\
\text { berpengalaman dalam bidang } \\
\text { ICT }\end{array}$ & w2 & $\begin{array}{llll}\text { Pertumbuhan revenue } & \text { dari IME } \\
\text { (Information, Media \& } & \text { Edutaiment) } \\
\text { belum memadai } & & \end{array}$ \\
\hline s3 & $\begin{array}{l}\text { Menguasai industri ICT di } \\
\text { tingkat regional }\end{array}$ & w3 & $\begin{array}{l}\text { Perangkat terletak pada geografis yang } \\
\text { tersebar di seantero nusantara }\end{array}$ \\
\hline S4 & Memiliki QoS yang baik & w4 & $\begin{array}{l}\text { Ketergantungan pada software dan } \\
\text { hardware import }\end{array}$ \\
\hline kode & Peluang (Opportunities) & kode & Ancaman (Threats) \\
\hline $\begin{array}{c}\text { Roue } \\
01\end{array}$ & $\begin{array}{l}\text { Besarnya pertumbuhan indus-tri } \\
\text { TIME (Telecommuni-cation, } \\
\text { Information, Media and } \\
\text { Edutaiment) / potensial market } \\
\text { di regional }\end{array}$ & Roue & $\begin{array}{l}\text { Banyaknya kompetitor bisnis dalam } \\
\text { bidang TIME }\end{array}$ \\
\hline 02 & Demand dari stakeholders tinggi & T2 & Pengoperasian BWA ke arah 4-G \& LTE \\
\hline 03 & $\begin{array}{l}\text { Next generation network menuju } \\
\text { broadband access yang } \\
\text { konvergen }\end{array}$ & T3 & Investasi infrastruktur ICT mahal \\
\hline 04 & $\begin{array}{l}\text { Daerah KTI (Kawasan Timur } \\
\text { Indonesia) perlu menambahkan } \\
\text { bandwidth }\end{array}$ & T4 & Perubahan teknologi ICT cepat \\
\hline
\end{tabular}

Letak titik X $=2.40-0.42=1.98$ (Koordinat titik X IFAS) Letak titik Y $=1.79-0.74=1.05$ (Koordinat titik Y EFAS)

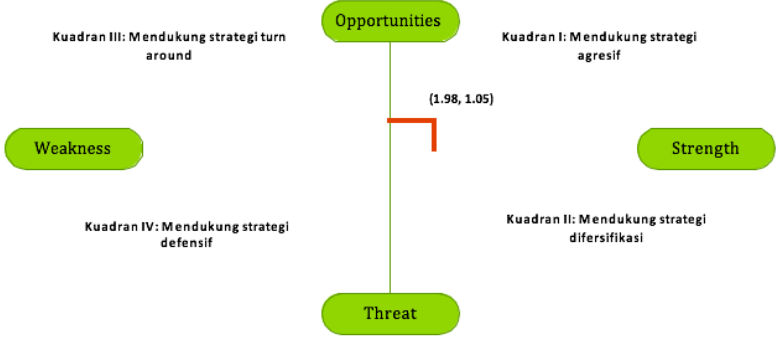

Gambar 3.Diagram Analisis SWOT

Gambar diatas menunjukan bahwa, posisi sub divisi satelit PT Telekomunikasi Indonesia berada di kuadran I, dimana perusahaan berada pada situasi yang sangat menguntungkan dikarenakan perusahaan memiliki peluang dan kekuatan sehingga dapat memanfaatkan peluang yang ada dengan sebaik - baiknya.

\section{IT Balanced Scorecard}

Penulis melakukan analisaIT Balanced Scorecard yang akan dari 4 (empat) perspektif diantaranya: kontribusi perusahaan, orientasi pengguna, penyempurnaan operasional dan orientasi masa depan. Hasil dari analisa ini bertujuan untuk mengetahui apakah sistem teknologi informasi yang digunakan telah mendukung visi, misi, dan tujuan perusahaan.

Balanced scorecard dapat diterapkan pada fungsi teknologi informasi, IT Balanced Scorecard (IT BSC) memiliki empat perspektif diantaranya sebagai berikut [6] :

- User Orientation, merupakan evaluasi pengguna user terhadap IT.

Operational Excellence, merupakan proses IT yang digunakan untuk mengembangkan dan mendukung aplikasi.

Future Orientation, perspektif sumberdaya manusia dan teknologi yang dibutuhkan oleh IT untuk memberikan layanannya.

Business Contribution, merupakan nilai bisnis yang diciptakan dari investasi IT

Tabel 5.Ringkasan Hasil Pengukuran Kinerja Sistem

\begin{tabular}{|l|l|}
\multicolumn{1}{|c|}{ Perspektif } & \multicolumn{1}{|c|}{ Hasil Pengukuran } \\
\hline $\begin{array}{l}\text { Perspektif Kontribusi } \\
\text { Perusahaan }\end{array}$ & $75 \%$ \\
\hline $\begin{array}{l}\text { Perspektif Orientasi } \\
\text { Pengguna }\end{array}$ & $79.44 \%$ \\
\hline $\begin{array}{l}\text { Perspektif Penyempurnaan } \\
\text { Operasional }\end{array}$ & $81.60 \%$ \\
\hline $\begin{array}{l}\text { Perspektif Orientasi Masa } \\
\text { Depan }\end{array}$ & $76 \%$ \\
\hline
\end{tabular}

Dari bobot diatas maka dapat disimpulkan hasil pengukuran dari empat perspektif IT Balanced Scorecard menunjukkan bahwa kinerja dari Sub Divisi Satelit PT Telekomunikasi Indonesia dapat dinilai dalam bobot atau kategori Very Good.

\section{REKOMENDASI STRATEGI SI/TI}

\section{SOA Service Oriented Architecture}

Alasan untuk menggunakan SOA diantaranya sebagai berikut [8]: Biaya Integrasi terus meningkat, dan tidak berkurang meskipun ada peluang untuk menghasilkan investasi pengembalian.

Merger dan akuisisi merupakan bisnis inti untuk memperluas pangsa pasar dan peluang pengembangan.

Solusi bisnis terintegrasi pada sistem dan model pemrograman yang heterogen.

Business survival bergantung pada kemampuan penyesuaian yang cepat pada perubahan pasar.

Efek ekonomi global meminta perusahaan untuk mengembangkan bisnis secara efisien.

- Perusahaan terdiri dari berbagai tipe bisnis.

- Perusahaan mulai mengembangkan aplikasi baru

Saat ini perusahaan memiliki aplikasi TeNOSS untuk mengintegrasikan data pada billing system, namun masih belum semua aplikasi terintegrasi ke TeNOSS, untuk penyeragaman interface dan protokol yang digunakan, salah satu 
rekomendasinya adalah dengan SOA (Service Oriented Architecture). Berikut penjelasan mengenai SOA yang dapat menjadi rekomendasi untuk Sub Divisi Satelit.

SOA (Service Oriented Architecture) adalah sebuah konsep software architecture yang mendefinisikan penggunaan layanan untuk mendukung kebutuhan pengguna software. Pendorong perkembangan SOA dari segi bisnis dikarenakan perusahaan memiliki skala sistem yang besar dan menjadikan internet sebagai salah satu penyedia layanan dengan tujuan untuk dapat mengintegrasikan aplikasi secara just-in-time.

\section{Knowledge Management}

Manajemen pengetahuan adalah ilmu penelitian yang komprehensif yang menekankan pertukaran informasi antar orang tetapi tidak menghilangkan pengetahuan yang telah ada. Manajemen pengetahuan adalah proses manajemen berkesinambungan dengan berbagai jenis pengetahuan. Manajemen pengetahuan juga merupakan semacam kemampuan yang membuat penggunaan bakat kelompok kerja untuk meningkatkan inovasi[7].

KAMPIUN diimplementasikan mulai tahun 2005 dimana staf masih belum menyadari pentingnya penggunaan aplikasi KAMPIUN dan rendahnya minat karyawan terhadap aplikasi tersebut. Mulai tahun 2006 dibuat kebijakan adanya sistem reward sehingga mempengaruhi nilai performa karyawan. KAMPIUN belum dimanfaatkan secara maksimal dalam berbagi pengalaman antar karyawan dan kegiatan problem solving operasional perusahaan.

Sebaiknya perusahaan menyadari pentingnya dukungan dari pihak manajemen dalam mengunakan manajemen pengetahuan pada KAMPIUN, akses KAMPIUN yang mudah dan user friendly, pendokumentasian pelatihan disimpan pada KAMPIUN, dokumentasi tidak hanya berbentuk dokumen namun dapat berbentuk suara dan video sehingga lebih menarik. Diharapkan perusahaan dapat mengoptimalisasikan KMS (Knowledge Management Sysytem) sehingga permasalahan yang ada dapat diminimalisasi dan dapat meningkatkan kinerja staf Sub Divisi Satelit.

\section{KESIMPULAN DAN SARAN}

Dari hasil analisis strategi penerapan teknologi informasi dengan menggunakan metode SWOT dan IT Balanced Scorecard studi kasus pada PT Telekomunikasi Indonesia Sub Divisi Satelit, dapat siambil simpulan sebagai berikut :

1. Berdasarkan hasil analisis faktor lingkungan internal dan lingkungan eksternal yang ada pada matriks SWOT, PT Telekomunikasi Indonesia Sub Divisi Satelit berada pada kuadran $\mathrm{S}-\mathrm{O}$ dengan titik koordinat (1.98 dan 1.05) dimana perusahaan berada pada situasi yang sangat menguntungkan dikarenakan perusahaan memiliki peluang dan kekuatan sehingga dapat memanfaatkan peluang yang ada dengan sebaik - baiknya.

2. Berdasarkan hasil analisis IT Balanced Scorecard dari hasil pengukuran perspektif kontribusi perusahaan sebesar $75 \%$, perspektif orientasi pengguna sebesar $79.44 \%$, perspektif penyempurnaan operasional sebesar $81.60 \%$, perspektif orientasi masa depan sebesar 76\%. Secara umum hasil analisis IT Balanced Scorecard pada Sub Divisi Satelit adalah sangat baik, namun masih perlu untuk dikembangkan khususnya pada peningkatan produktivitas user yaitu ketepatan user dalam menyelesaikan pekerjaan dengan hasil pengukuran $72.5 \%$ dari $75 \%$ yang ditargetkan.

3. Berdasarkan analisis yang telah dilakukan dengan menggunakan metode SWOT dan IT BSC dihasilkan rekomendasi yaitu SOA (Service Oriented Architecture) dan KMS (Knowledge Management System). SOA(Service Oriented Architecture) dapat dikembangkan sebagai solusi bisnis terintegrasi pada sistem untuk melakukan penyeragaman interface dan protokol yang digunakan. KMS (Knowledge Management System) sebagai solusi aplikasi untuk masing masing pegawai, sehingga dapat melakukan sharing permasalahan mengenai sistem aplikasi yang dijalankan oleh perusahaan.

\section{DAFTAR PUSTAKA}

[1] Dan Remenyi, Frank Bannister, Arthur Money. The effective measurement and management of IT cost and benefits. Great Britain: Butterworth Heinemann; 2007

[2] Freddy Rangkuti. Analisis SWOT Teknik Membedah Kasus Bisnis. PT. Gramedia Pustaka Utama, Jakarta; 2000

[3] John Ward, Joe Peppard. Strategic Planning for Information Systems. Sussex: John Wiley \& Sons Ltd.; 2002

[4] Sri Nurhayati. Analisis Strategi Sistem Teknologi Informasi dengan Pendekatan Analisis SWOT (Studi Kasus: Divisi IT Rumah Sakit Mata Cicendo Bandung). Seminar Nasional Informatika 2009; 2009

[5] Surekha Durvasula. SOA Practitioner's Guide Part 3. Introduction to Services Lifecycle; 2006

[6] Wim Van Grembergen, Ronald Saull. Align Business and Information Technology through the Balanced Scorecard at a Major Canadian Financial Group: it Status Measured with an IT BSC Maturity Model. Proceedings of the $34^{\text {th }}$ Hawaii International; 2001

[7] Xin Shi, Shusen Zhang, Yuan li. Construction of Equipment Knowledge Management System. International Conference of Information Technology, Computer Engineering and Management Sciences; 2011

[8] Ying-Hong Wang, Jingo Chenghorng Liao. Why or Why Not Service Oriented Architecture. IITA International Conference on Service Science, Management and Engineering; 2009

\section{BIODATA PENULIS}

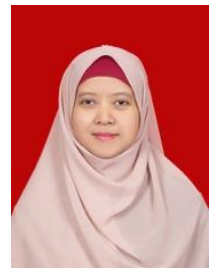

Sari Setyaning Tyas, lahir di Jakarta, 9 Maret 1987. Meraih gelar Sarjana Teknik Informatika (S.Kom) dan Magister Teknik Informatika (M.TI) dari Universitas Bina Nusantara Jakarta. Saat ini bertugas sebagai Dosen di Politeknik Negeri Media Kreatif program studi Teknologi Rekayasa Multimedia mengampu mata kuliah analisa perancangan multimedia, rekayasa perangkat lunak dan ui/ux. Penulis aktif dalam mengikuti seminar penelitian serta menulis pada jurnal penelitian ilmiah nasional. 